\title{
Polysulphone film as an underwater dosimeter for solar ultraviolet-B radiation in tropical latitudes
}

\author{
Richard P. Dunne* \\ Department of Marine Science and Coastal Management, University of Newcastle, Newcastle upon Tyne NE1 7RU, United \\ Kingdom
}

\begin{abstract}
This paper examines the potential of polysulphone film (PSF) as a dosimeter for unweighted solar ultraviolet- $B$ radiation (UVB; 280 to $320 \mathrm{~nm}$ ) in different seawater conditions in tropical latitudes. PSF's accuracy is determined by water type and depth range. The film may be used over a depth range of $7 \mathrm{~m}$ with measurement errors of less than $5 \%$ in oceanic type waters, such as are found around coral atolls and islands. In clear but coloured continental coastal waters the range decreases to $2.2 \mathrm{~m}$. Calibration functions are presented for use of the film both in air (e.g. an intertidal setting) and underwater over the UVB dose range of about 1.5 to $40 \mathrm{~kJ} \mathrm{~m}^{-2}$ A comprehensive analysis of errors arising from the use of PSF, in air and underwater, is given. The film offers a cost-effective and simple technique for studying biological responses to solar UVB radiation in many tropical marine habitats, including intertidal and subtidal coral reefs.
\end{abstract}

KEY WORDS: Solar UVB · Dosimeter · Coral reefs · Tropics

\section{INTRODUCTION}

Accurate measurement of solar ultraviolet-B (UVB; 280 to $320 \mathrm{~nm}$ ) radiation above and below the water surface in marine ecosystems is crucial to our understanding of the effects of this portion of the solar spectrum on living organisms

Although UVB represents less than $1 \%$ of the total energy of the solar spectrum reaching the earth's surface, the high energy in each quantum at these short wavelengths damages some of the most important biological processes, the principal target being the DNA molecule (Jagger 1985), although protein damage also occurs (Häder 1997).

Accurate measurements of UVB are technically difficult to achieve. A variety of techniques and instrumentation has been developed, each with its own advantages and drawbacks, which include considerations of complexity, cost, convenience, sensitivity, and accuracy. The methodologies give rise to a generalised separation of data into 2 types, namely instantaneous measurements and measurements integrated over

•E-mail: 101515.1267@compuserve.com time (dosimetry). Instantaneous measurements of irradiance $\left(\mathrm{W} \mathrm{m}^{-2}\right)$ can only be achieved effectively using scanning or narrow-band spectroradiometry. Although such measurements may be accumulated over time to allow computation of dose, the practicality of continuous spectroradiometry is more often severely limited by the complexities of the instruments, their expense, and problems of power, portability and stability over time. Dosimetry, on the other hand, is largely undertaken using biological or chemical indicators. It is with these latter techniques that this paper is concerned.

A number of chemical and biological dosimetry techniques for measuring solar UVB radiation have been proposed over the last $20 \mathrm{yr}$. Biological methods include the use of bacterial strains of Escherichia coli (CSR06) deficient in DNA repair mechanisms (Karentz \& Lutze 1990), dried spores of Bacillus subtilis (Quintern et al. 1992), ${ }^{14} \mathrm{C}$ thymidine-labelled DNA and bacteriophage (ØX174 DNA (Regan et al. 1992), measurements of cyclobutane pyrimidine dimers (Jeffrey et al. 1996), and solutions containing DNA molecules (Boelen et al. 1999). Chemical dosimetric techniques have involved polymer films such as polysulphone (PSF) (Davis et al. 1976), allyl diglycol carbonate (CR-39) (Wong et al. 1989), a composite system of nalidixic 
acid, 8-methoxysaralen, phenothiazine, PSF (Parisi \& Wong 1996) and o-nitrobenzaldehyde (Fleischmann 1989).

The biological techniques almost exclusively record UVB damage to DNA and subsequent evaluation of this damage using radiochromatographic assays, plaque formation, or dye staining techniques. Since the prime target for UVB damage in biological systems is DNA (Jagger 1985), these techniques have an advantage in that they incorporate precisely the DNA action damage spectrum into their results. Their overwhelming disadvantage is that they all involve labourintensive and complex procedures. They also do not lend themselves to studies involving other biological effects of UVB such as the erythemal response in humans (sunburn), and it is by no means certain that whole organism responses to UVB can be directly related to DNA damage alone. Consequently they tend to be used only in DNA related studies and to date there are few indications that they have been used extensively.

Chemical dosimetry techniques are invariably simpler. However, the main drawback of these techniques is that the wavelength responses of the various polymer films are neither uniform across the UVB waveband (i.e. recording unweighted UVB), nor do they mimic any known biological action spectrum. One technique proposed by Fleischmann (1989) uses a chemical whose spectral sensitivity extends well into the UVA (320 to $400 \mathrm{~nm}$ ) portion of the spectrum, necessitating the use of cut-off filters to adjust its response to UVB. In addition, a build up of the reaction product causes artifacts in the radiation measurements (Morales et al. 1993). A better technique uses a polymer (CR-39) (Wong et al. 1989), which has a spectral response that rapidly tails off at wavelengths above $300 \mathrm{~nm}$, mimicking the human erythemal response and making it suitable for both unweighted UVB dosimetry and biologically relevant studies; this technique suffers however from the requirement of etching the film chemically after UV exposure before determining optical density as a measure of UVB dose. More recent composite systems of Parisi \& Wong (1996) probably offer greater flexibility, allowing as they do for biologically effective exposure for any biological process to be calculated with a better than $20 \%$ accuracy; however, preparation and availability of the material at present limit the benefits of this technique.

Of all the techniques, PSF currently offers the greatest likely benefits. Its spectral sensitivity is relatively flat between 280 and $310 \mathrm{~nm}$, thereafter reducing sharply to $32 \%$ at $320 \mathrm{~nm}, 4 \%$ at $330 \mathrm{~nm}$, and ceasing to respond to wavelengths above $340 \mathrm{~nm}$ (Davis et al. 1976, CIE 1992). Its response is independent of dose rate (Bunsen-Roscoe law). The chemical constituent in the film (polysulphone) darkens following exposure to ultraviolet radiation, and its dose response can be assessed by measuring its change in absorbance at 330 $\mathrm{nm}$ using a spectrophotometer. Furthermore, it is robust, environmentally stable, easy to use, and commercially available at relatively low cost. It is hardly surprising, therefore, that it has been used extensively in human erythemal studies (Diffey 1989) and later in plant studies (Parisi \& Wong 1994). Apart from some work by Diffey (1989) little has been published concerning its ability to resolve small differences in dose, or to identify the full range of errors associated with its use. This is understandable in the context of its use in human erythemal studies where research is primarily concerned with relatively large differences in dose. While it can be used to record both unweighted or biologically relevant UVB, it must be calibrated appropriately. Examples of previous unweighted calibrations in air using $40 \mu \mathrm{m}$ thick film can be found in Parisi \& Wong (1994) for the waveband 280 to $340 \mathrm{~nm}$, in Webb (1985) for wavelengths 300 to $316 \mathrm{~nm}$, and a generalised calibration function in Diffey (1989). Although its use underwater has been mentioned (Davis 1977), no investigation of this application has been undertaken.

The purpose of this paper is to examine the potential for using PSF in an intertidal and underwater environment, to examine its resolving power and the range of errors involved with its use, and to present a calibration for the recording of unweighted UVB (280 to $320 \mathrm{~nm}$ ) both in air and underwater for the currently available $50 \mu \mathrm{m}$ film thickness. Specifically, I will cover the following areas: (1) Measurement of absorbance changes in the film and the choice of spectrophotometer, (2) errors associated with changes in the solar spectrum during the course of a day, at different latitudes, weather conditions, and in different water types and at different depths, (3) calibration functions and their accuracy in dose computation.

\section{MATERIALS AND METHODS}

Commercially available PSF can be purchased from the Regional Medical Physics Department, Newcastle General Hospital, Newcastle upon Tyne NE4 6BE, United Kingdom. Film is supplied in roll form, $60 \mathrm{~cm}$ wide, $50 \mu \mathrm{m}$ thick. Cut sections of film were mounted in conventional plastic $35 \mathrm{~mm}$ glassless slide mounts, giving an area of $23 \times 35 \mathrm{~mm}$ for exposure to solar UVB radiation. Although sufficiently robust for most applications, the planned use of the film in a marine intertidal setting, coupled with the requirement to block UVB from entering the film from the reverse side, involved the insertion of an additional polymer film in 
the mount during field deployment. Many types of film would prove suitable for this purpose; in this case $40 \mu \mathrm{m}$ thick Sun-Gard window film (NRW 400 C90 PS SCR 19412, Bonwyke Ltd, 41 Redlands Lane, Fareham, Hants PO14 1HL, United Kingdom) was used. The spectral transmission properties of this material are illustrated in Fig. 1. It blocks all UVR below $340 \mathrm{~nm}$.

\section{UVB dose computation using PSF}

In order to compute UVB dose, the absorbance of the film is measured at a wavelength of $330 \mathrm{~nm}$. At this wavelength the film is slightly opaque and errors in the absorbance reading due to scattering can arise. To investigate the effect of these errors, measurements of the optical density of the film were made using a typical laboratory spectrophotometer (Hewlett Packard HP8452A single beam, reverse optic diode array design; for full specification see Dunne 1999) and compared with results obtained from a Macam Photometrics SR9910 spectroradiometer (see Dunne \& Brown 1996) fitted with fibre optic attachments and using a stabilised quartz halogen lamp source.

For routine measurements of films deployed in the field the SR9910 spectroradiometer was used, since its design eliminates the need to correct readings for scattering effects. Pre- and post-absorbance measurements of optical density were made at $330 \mathrm{~nm}$ from the same 2 circular areas $\left(1.77 \mathrm{~cm}^{2}\right)$ on each slide. Each absorbance reading was the mean of $20 \times 500$ analogue to digital (ADC) samples. The change in optical

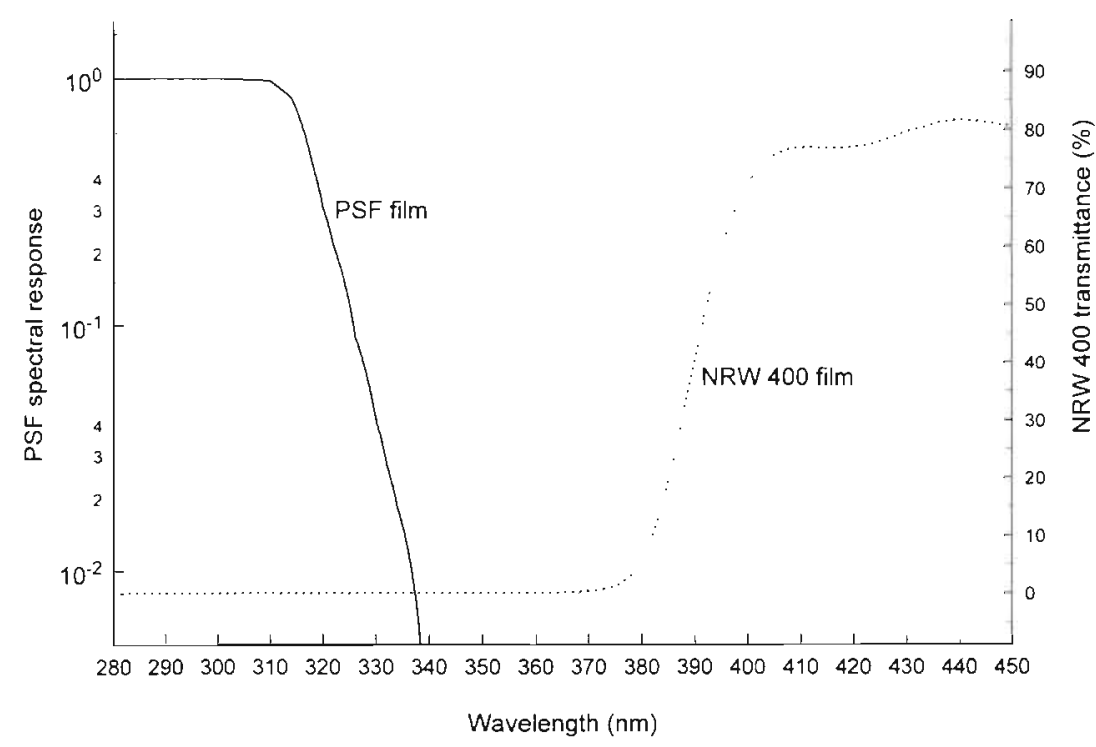

Fig. 1. Spectral response of PSF between 280 and $340 \mathrm{~nm}$ (after Davis et al. 1976), and transmittance of NRW 400; a UVB blocking polymer film (below $340 \mathrm{~nm}$ NRW 400 transmits less than $0.05 \%$ ) density $\left(\Delta A_{330}\right)$ was computed from each pair of readings. All films were subjected to minimum handling (where necessary surgical gloves were used) to avoid grease and other contamination. Films deployed underwater in field conditions were cleaned before measurement, using freshwater, and air-dried; gentle brushing with a soft toothbrush during this process had no adverse effect. Measurements of post-exposure absorbance were made $12 \mathrm{~h}$ after exposure. In all other respects the protocols in Diffey (1989) were followed.

\section{Errors due to changes in the solar spectrum during the course of a day, at different locations, and in different water types and depths}

In order to compute the errors due to the non-linear spectral sensitivity of PSF and changes in the spectral distribution of solar UVB, scans of global downwelling irradiance $\left(E_{\mathrm{d}}\right)$ were made using the SR9910 spectroradiometer equipped with a $2 \pi$ cosine corrected sensor following the procedures in Dunne \& Brown (1996). The response of the PSF $\left(E_{\mathrm{PSF}}\right)$ was then computed by weighting the recorded UVR irradiance by the PSF spectral sensitivity as defined by Davis et al. (1976), so that:

$$
E_{\mathrm{PSF}}=\int_{340}^{280} E_{\mathrm{d}}(\lambda) \varepsilon_{\mathrm{PSF}}(\lambda) \mathrm{d} \lambda
$$

where $E_{\mathrm{d}}(\lambda)$ is the global downwelling solar irradiance at wavelength $\lambda$, and $\varepsilon_{\mathrm{PSF}}(\lambda)$ is the spectral sensitivity at wavelength $\lambda$ normalised to 1 at $300 \mathrm{~nm}$. The integral 280 to $340 \mathrm{~nm}$ represents the shortest wavelength of UVR reaching the earth's surface (280 nm), and the upper limit of the PSF response $(340 \mathrm{~nm})$. Differences between the ratio of unweighted UVB to the computed PSF response were then used to calculate errors under different environmental conditions.

\section{Calibrations}

The film was calibrated for unweighted solar UVB over 3 d (22 January 1998, 20 and 21 February 1999) under cloudless tropical skies at Phuket, Thailand $\left(7^{\circ} 49.9^{\prime} \mathrm{N}\right.$, $98^{\circ} 25.5^{\prime} \mathrm{E}$ ) against solar UVB irradiance data from spectroradiometer scans. The underwater calibration 
was conducted with the slides and spectroradiometer sensor submerged $5 \mathrm{~cm}$ underwater in a shallow aquarium. In both the air and underwater calibrations the slides were mounted horizontally directly adjacent to the spectroradiometer input sensor. Slides were deployed for various exposure periods between 08:30 and 16:30 h. A total of 47 slides was used for the underwater calibration. For the air calibrations 48 slides were used on 21 February 1999, and a further 8 on 22 January 1998. Two replicate measurements of absorbance were taken from different areas on each slide. Use of the UVB blocking film (NRW 400) behind each slide ensured that the film received the same solar radiation field as the $2 \pi$ cosine corrected input of the spectroradiometer. The spectroradiometer was set to scan at 1 min intervals between 280 and $400 \mathrm{~nm}$ (step length $1 \mathrm{~nm}, 200 \mathrm{ADC}$ conversions, scan time $40 \mathrm{~s}$ ); pre-calibration and wavelength checks were made against secondary lamp sources traceable to National Physical Laboratory (UK) standards. Maximum solar altitudes on the days were $62.5^{\circ}$ (at $12: 38 \mathrm{~h}$ ) on $22 \mathrm{Jan}$ uary 1998 , and $71.1^{\circ}$ and $71.5^{\circ}$ at $12: 40 \mathrm{~h}$ on 20 and 21 February 1999, respectively. The spectroradiometer measurements for the underwater calibration were adjusted for the 'immersion effect' (Tyler \& Smith 1970).

\section{Statistical testing}

Statistical comparisons of data were made using GraphPad InStat V 3.0 (GraphPad Software, Inc). Assumptions of normality were satisfied in all cases (Kolmogorov and Smirnov method). Homoscedastic data sets were analysed using parametric ANOVA and multiple post hoc testing, whilst non-parametric tests were used for heteroscedastic data. In all cases the probability was adjusted to maintain $\alpha=0.05$

\section{RESULTS AND DISCUSSION}

\section{Measurement of absorbance changes in the film and choice of spectrophotometer}

The computation of UVB dose requires measurement of the absorbance of the PSF, at a wavelength of $330 \mathrm{~nm}$, pre- and post-exposure to solar UVB. The change in absorbance $\left(\triangle A_{330}\right)$ is then used in conjunction with a calibration function to compute the UVB dose (Diffey 1989). In earlier studies, no particular regard was paid to the optical configuration or type of spectrophotometer used for these measurements. Visual inspection of PSF, however, shows a degree of opacity which will give rise to scattering of the spectrophotometer measurement beam. The $A_{330}$ for unexposed film typically gives a value of about $0.09 \mathrm{~A}$ (Fig. 2) using an optical configuration which removes any scattering effect (SR9910 with fibre optic input). However, use of spectrophotometers which are configured for simple transmission measurements of optically clear samples may give rise to considerable errors. One such instrument (Hewlett Packard HP8452A) gave a high reading of $A_{330}=0.46$ (Fig. 2) due to the scattering losses. Applying a simple baseline correction using the absorbance at $400 \mathrm{~nm}(0.347 \mathrm{~A})$ removes most of the scattering error, so that $A_{330}$ becomes 0.11 , a value which still contains an error about $22 \%$ above the true absorbance. The consequence of scattering will therefore be important when the pre- and post-absorbance measurements are made with optically different instruments, or even at different points along the optical path of the same instrument. Most of the errors can be avoided if both measurements are taken with the same instrument. In the case of the example in Fig. 2, measurements for the same sample of film gave a value of $\Delta A_{330}$ $=0.423$ from the SR9910 (no scattering losses) compared with 0.452 from the HP8452A, a difference of $7 \%$. Although this may be acceptable in experiments

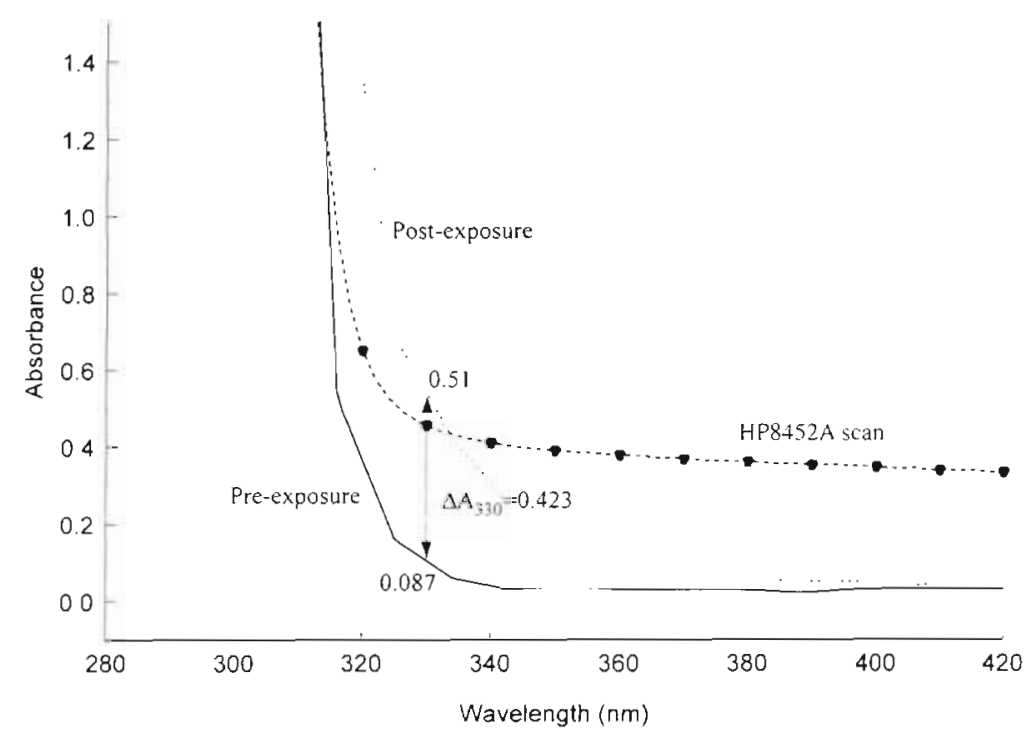

Fig. 2. Spectra] absorbance of $50 \mu \mathrm{m}$ PSF before and after exposure to solar UVB radiation. Solid line: absorbance before exposure; dotted line: absorbance after exposure. The dose was approximately $12 \mathrm{~kJ} \mathrm{~m} \mathrm{~m}^{-2}$ and resulted in a change in absorbance of 0.423 measured at $330 \mathrm{~nm}$. Both measurements were made with the SR 9910 spectroradiometer. Dashed line with circles: scan of the same portion of film before exposure using a Hewlett Packard HP8452A spectrophotometer, and illustrating the effect of scattering on the measurements 
where only large differences in dose are being compared and absolute units of UVB dose are not required, nonetheless it illustrates the care that should be exercised. Ideally, measurements should be made with a spectrophotometer designed to measure transmission through opaque samples (e.g. with fibre optic, preying-mantis, or integrating sphere attachments).

\section{Changes in the solar spectrum over the course of a day}

Changes take place in the spectral power distribution of UVR over the course of a solar day, due primarily to the variation in the atmospheric path length of the direct solar beam. As a result, PSF used to record UVB dose for different portions of a day would be expected to contain measurement errors. The most extreme errors are likely to arise when the variation in atmospheric path length is greatest, i.e. on days when the solar zenith is directly overhead (sun altitude $90^{\circ}$ ). In the present examination, above water spectroradiometer scans for 22 January 1998 at Phuket, Thai-
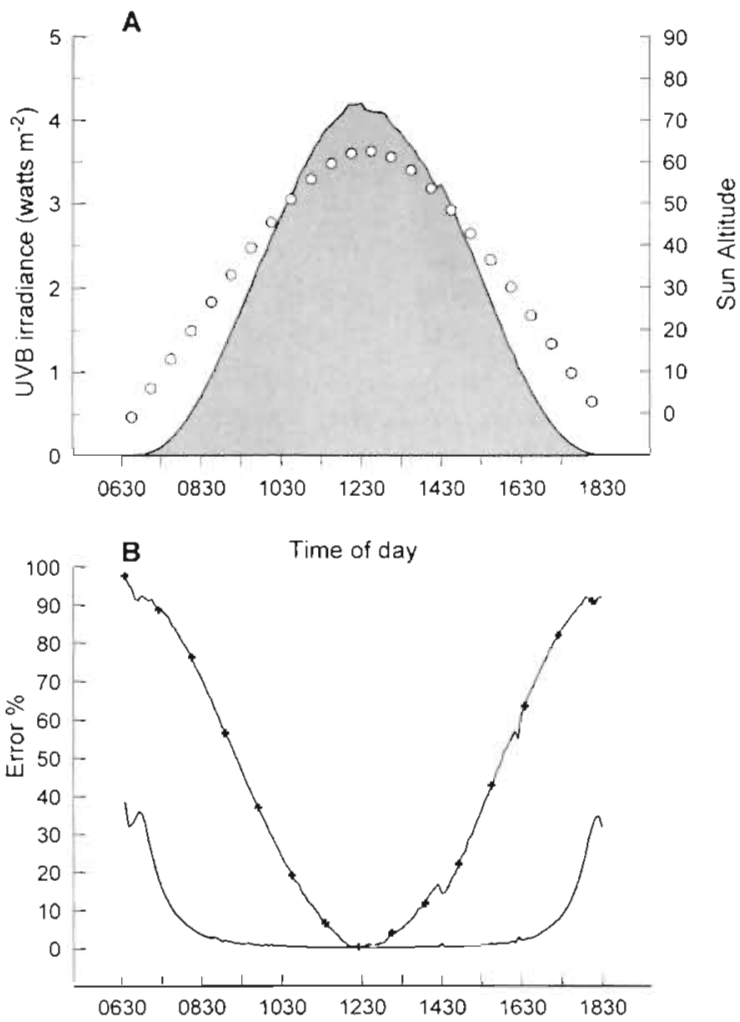

Fig. 3. (A) Solar UVB (280 to $320 \mathrm{~nm}$ ) irradiance from dawn (06:30 h) to dusk (18:30 h) at Phuket, Thailand, on a clear-sky day (22 January 1998) - solid area; sun altitude (degrees above the horizon) - open circles. (B) Percentage errors associated with the use of PSF to record UVB at different times of the day - solid line; and to predict DNA damage - line with symbols land, recorded every 5 min $(n=144)$ were used. Maximum sun altitude was $62.5^{\circ}$. Fig. 3 shows the diurnal variability in the unweighted UVB irradiance and the PSF response spectral errors. Between 9:00 and 16:30 h (sun altitudes $30^{\circ}$ and $27^{\circ}$, respectively) the error between the UVB and the PSF response ( $\left.E_{\mathrm{PSF}}\right)$ is less than $2 \%$. At lower sun altitudes the error progressively increases, reaching $5 \%$ error for a sun altitude of $20^{\circ}$ (before $8: 15$ and after $17: 05 \mathrm{~h}$ ) and $10 \%$ for an altitude of $13^{\circ}$ (before $07: 45$ and after 17:35 h). Sunrise was at 6:45 h and sunset at 18:30 h.

The extent of sun altitude errors on the use of PSF at different tropical latitudes can be illustrated by considering the annual variation in day length and the solar zenith. Within the tropics (N/S $23^{\circ} 27^{\prime}$ ) the day length varies between a maximum of $13.5 \mathrm{~h}$ and a minimum of $10.5 \mathrm{~h}$ at the northern and southern extremities; in between the variation is smaller. For all tropical latitudes the length of time that the sun altitude is below $20^{\circ}$ is largely independent of time of year and latitude, and represents $1.5 \mathrm{~h}$ at the beginning and end of each day. Similarly, the variation in the solar zenith within the tropics will be maximum at the extremities, from a minimum altitude of $43^{\circ}$ to a maximum of $90^{\circ}$ depending on the time of year. Use of the film at any tropical latitude for the major part of any day will therefore be well within an error bracket of $\pm 5 \%$. Where the film is only deployed for short periods at the beginning and end of daylight hours, errors will be unacceptably high. In practical terms, however, the dose of UVB and therefore the change in absorbance recorded by the film in the first and last hour and a half of daylight is so small as to be below the reliable range of the calibration curves (0.1 $\left.\Delta A_{330}\right)$. Where longer periods of deployment include these early and late times of day the error contribution diminishes geometrically (Table 1), and is in any event subsumed into the overall calibration error (see 'Calibration of PSF for unweighted UVB solar radiation').

Fig. 3 also shows the potential errors which would be associated with the use of PSF to record DNA damage (based on the action spectrum of Setlow 1974). In this particular case it can be seen that the errors are unacceptably large, because of the large disparity between the wavelength response of PSF and the DNA action damage spectrum. PSF does not therefore behave as an accurate proxy for DNA damage.

\section{Cloud effects}

Clouds and atmospheric aerosols are known to have little effect on the spectral quality of solar UVB (Zerefos 1997). Nonetheless, in order to determine the magnitude of any effect, the ratio of the UVB/PSF response was 
compared between a clear-sky day (22 January 1998) and a heavily overcast day (18 March 1994) at Phuket. To avoid effects due to changing atmospheric path length, only data between 10:26 and 14:55 h were compared. Although there was a significant difference (Mann Whitney test, $\mathrm{p}<0.0001$ ) between the ratios under the 2 different conditions (cloudy day ratio $1.0971 \pm 0.0082 \mathrm{SD}, \mathrm{n}$ $=10_{i}$ clear-sky ratio $1.0893 \pm 0.0022 \mathrm{SD}, \mathrm{n}=54$ ) the percentage variability only amounts to $0.72 \%$. Fig. $4 \mathrm{~A}$ shows the range of individual data points and the variation in the irradiance for these 2 days.
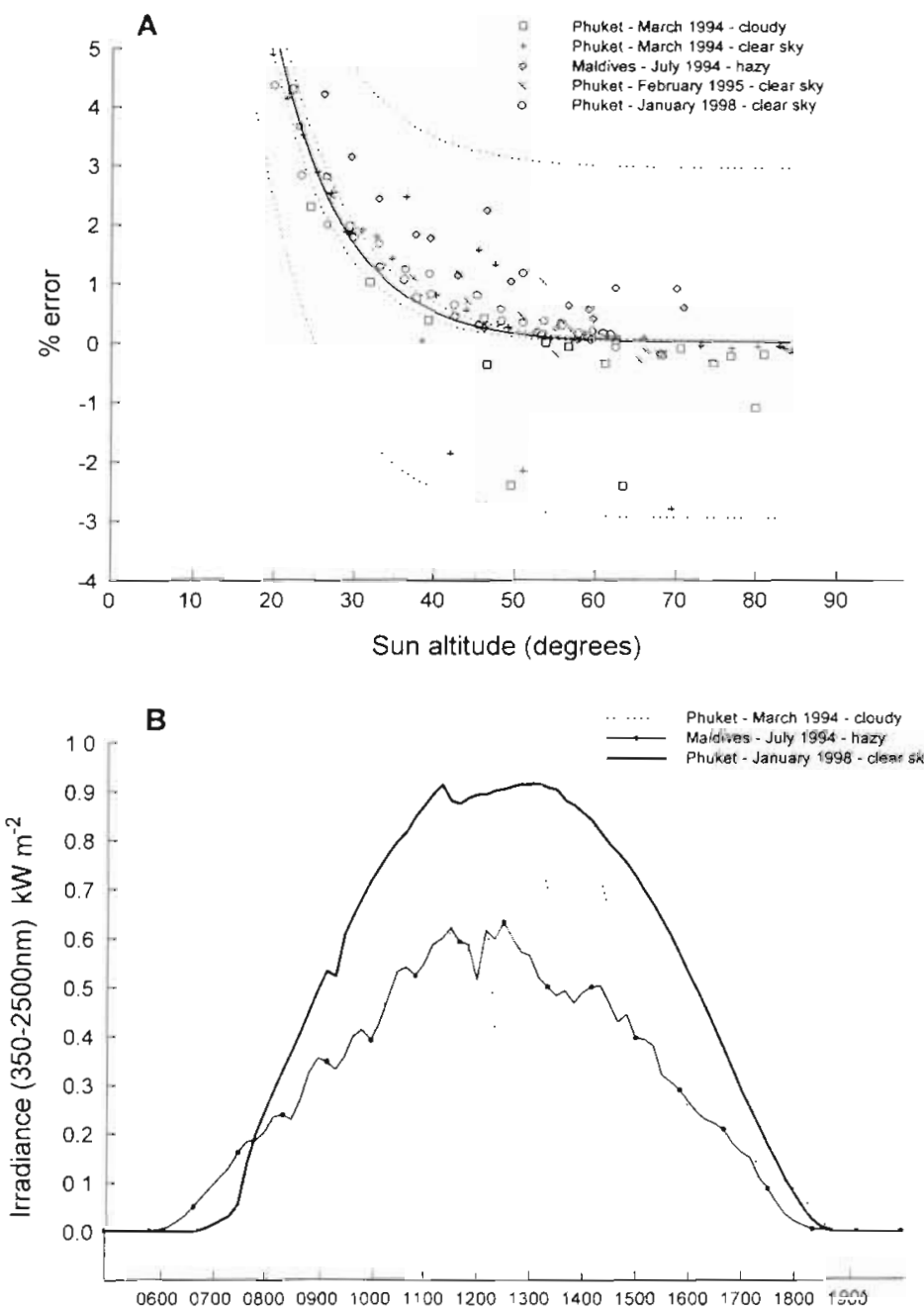

Fig. 4. (A) Errors in the use of PSF for recording unweighted solar UVB (280 to $300 \mathrm{~nm}$ ) as a function of sun altitude for different months, locations, and weather conditions in the tropics. At solar altitudes $<20^{\circ}$ the errors are $>5 \%$. The best fit relationship is shown by the continuous line $\left(r^{2}=0.96, p<\right.$ $0.001, n=136$ ), together with the $99 \%$ confidence (inner) and prediction intervals (outer dotted lines). (B) Solar irradiance (350 to $2500 \mathrm{~nm}$ ) recorded for days on which data in (A) were collected. The clear sky days from Phuket in March 1994 and February 1995 were substantially the same as for January 1998 and have been omitted for clarity
Table 1. Percentage errors due to solar spectral changes in the use of PSF to record unweighted UVB (280 to $320 \mathrm{~nm}$ ) over different time periods for a tropical location (Phuket, Thailand; $7^{\circ} 49.9^{\prime} N 98^{\circ} 25.5^{\prime} E_{i} 22$ January 1998). These errors are normalised to the UVB spectrum between 11:30 and 12:30 h, and assume a linear calibration function. In practice the calibration function is polynomial and the errors for the cumulative time periods will therefore be very much reduced. The positive sign of the error means that the PSF overestimates UVB

\begin{tabular}{|cccc|}
\hline $\begin{array}{c}\text { Hourly deployment } \\
\text { periods }\end{array}$ & $\begin{array}{c}\text { Error } \\
(\%)\end{array}$ & $\begin{array}{c}\text { Cumulative deploy- } \\
\text { ment periods }\end{array}$ & $\begin{array}{c}\text { Error } \\
(\%)\end{array}$ \\
\hline $06: 30-07: 30$ & +29 & $06: 30$ to & \\
$07: 30-08: 30$ & +6.9 & $08: 30$ & +8.4 \\
$08: 30-09: 30$ & +2 & $09: 30$ & +3.5 \\
$09: 30-10: 30$ & +0.7 & $1.0: 30$ & +1.9 \\
$10: 30-11: 30$ & +0.2 & $11: 30$ & +1.1 \\
$11: 30-12: 30$ & 0 & $12: 30$ & +0.7 \\
& & & \\
\hline
\end{tabular}

\section{Latitude, seasonal and weather condition effects}

In Fig, 4 the effects of different months, latitude, and weather conditions are compared. The percentage errors shown are the extent to which the ratio of solar UVB/PSF response will vary when compared to clearsky conditions and high sun altitude $112: 30 \mathrm{~h}$ at Phuket on 22 January 1998 , sun altitude $62.5^{\circ}$ ). Although this is not a comprehensive latitude and seasonal analysis for the whole tropical region, nonetheless it might be expected to reveal whether significant differences are likely to be found. The data cover a total of 4 different months (January, February, March, July) from 2 different locations (Phuket $7^{\circ} \mathrm{N}$, Maldives $4^{\circ} \mathrm{N}$ ) and 2 different weather conditions (clear days, overcast day). As might be expected from Fig. 3B there is an exponential relationship of increasing error with decreasing sun altitude $\left(r^{2}=0.96, p<0.0001, n=136\right)$. The $99 \%$ confidence interval demonstrates that errors of less than $\pm 5 \%$ will be found for sun altitudes above $21^{\circ}$, similar to the earlier findings for a single location under clear sky conditions.

Table 2 extends this comparison to a further range of years and includes a comparison to a high-latitude site $\left(54^{\circ} \mathrm{N}\right)$ for May and January. Even the high-latitude site shows good comparison during the early summer, whilst a major contribution to the high error (26\%) at this site for January is likely to be the very low sun altitude $\left(12.7^{\circ}\right.$ - the maximum on this day did not exceed $13^{\circ}$ ) and can be compared to values of $10 \%$ obtained for similarly low sun altitudes at the tropical sites. The additional error is possibly due to differences in stratospheric ozone. 
Table 2. Percentage error in the PSF response to solar UVB at 2 tropical, and 1 high-latitude location for different months and years. The error is expressed as the percertage difference between the UVB/PSF ratio at each location and at the calibration site (Phuket) at 12:30 h on 22 January 1998

\begin{tabular}{|c|c|c|c|c|c|}
\hline Location & Date & Latitude & Longitude & $\begin{array}{c}\text { Sun altitude } \\
\left({ }^{\circ}\right)\end{array}$ & $\begin{array}{c}\text { Error } \\
(\%)\end{array}$ \\
\hline \multicolumn{6}{|l|}{ Tropical sites } \\
\hline Phuket & $\begin{array}{c}28 \text { Mar } 94 \\
10 \text { Feb } 95 \\
14 \text { Feb } 96 \\
4 \text { Feb } 98\end{array}$ & $8^{\circ} \mathrm{N}$ & $98^{\circ} \mathrm{E}$ & $\begin{array}{l}52 \\
65 \\
55 \\
48\end{array}$ & $\begin{array}{c}2.4 \\
-0.1 \\
0.07 \\
0.44\end{array}$ \\
\hline Ko Racha Yai, Phuket & 21 Feb 95 & $7^{\circ} 36^{\prime} \mathrm{N}$ & $98^{\circ} \mathrm{E}$ & 70 & 0.1 \\
\hline Maldives & $\begin{array}{l}6 \text { Jul } 94 \\
7 \text { Jul } 94\end{array}$ & $4^{\circ} \mathrm{N}$ & $73^{\circ} \mathrm{E}$ & $\begin{array}{l}48 \\
57\end{array}$ & $\begin{array}{l}-0.2 \\
1.61\end{array}$ \\
\hline $\begin{array}{l}\text { High latitude site } \\
\text { Mickleton, UK }\end{array}$ & $\begin{array}{c}7 \text { May } 93 \\
11 \text { May } 93 \\
17 \text { Jan } 94\end{array}$ & $54^{\circ} \mathrm{N}$ & $2^{\circ} \mathrm{W}$ & $\begin{array}{c}52 \\
46 \\
12.7\end{array}$ & $\begin{array}{c}2.4 \\
-0.3 \\
26\end{array}$ \\
\hline
\end{tabular}

\section{Changes in stratospheric ozone concentration}

Natural seasonal variation in stratospheric ozone concentration in the tropical belt is relatively small (240 to 280 Dobson Units [DU]) compared to that in high latitudes, e.g., $52^{\circ} \mathrm{N}$ (280 to $400 \mathrm{DU}$ ) (Cutchis 1982). Webb (1985) examined the use of the film for recording unweighted solar UVB (300 to $316 \mathrm{~nm})$ at $52^{\circ}$ $\mathrm{N}$ and showed that a single calibration function would hold good for any changes of ozone between the months o: May and August (321 to 393 DU; range 72 DU), and similarly between October and January (273 to $366 \mathrm{DU}$; range $93 \mathrm{DU}$ ). This implies that the small annual range of stratospheric ozone of only 40 DU in the tropics is unlikely to have any significant effect on the use of the film at any tropical location at any time of year.

\section{Effects due to different water types and difierent depths}

The penetration of solar radiation underwater is influenced by a number of factors which reduce the overall radiant energy and also selectively attenuate different wavelengths. The primary factors causing attenuation are water colour and turbidity. The former is largely due to the dissolved organic carbon (DOC) content, and the latter a consequence of the suspended particulate matter. In addition, the water molecules also absorb selectively at different wavelengths. In different water types and at different depths, therefore, the solar spectrum will be markedly different from the above water spectrum. The spectral variation is particularly acute in the shorter wavelength UVR bands. For the purpose of the computation of errors associated with the use of PSF as an unweighted UVB dosimeter, 3 previously studied water types are used in this paper. All 3 are fully described in an earlier paper (Dunne \& Brown 1996); they are (1) clear oceanic water from a midocean atoll island lagoon (North Malé, Maldives, Indian Ocean), (2) clear but green coloured water around a continental high island (Ko Racha Yai, Phuket, Thailand, Andaman Sea), and (3) highly turbid and very green coloured water adjacent to a continental land mass (Phuket Marine Biological Center [PMBC], Thailand, Andaman Sea). At each of these sites spectroradiometer scans of downwelling irradiance have been recorded and the attenuation coefficients computed for the full solar spectrum (280 to $700 \mathrm{~nm}$ ) over a depth range from the water surface to $5 \mathrm{~m}$ (Dunne \& Brown 1996). These scans were used to compute the PSF response in this paper.

The errors associated with the use of the PSF are summarised in Table 3 , expressed as the percentage by which the film overestimates the unweighted UVB due to spectral changes at each depth and in each water type compared to its use at the water surface.

Table 3. Depth-dependent mean percentage error ( \pm SD) for PSF as an underwater dosimeter of solar UVB radiation (280 to $320 \mathrm{~nm}$ ) in different water types. Data extracted from spectroradiometer scans at each depth $(7$ scans at Maldives and Ko Racha Yai, and 14 at PMBC [Phuket Marine Biological Center]). Diffuse attenuation coefficient for downwelling irradiance $\left(K_{d}\right)$ at $320 \mathrm{~nm}$ included for cross-comparison (see Dunne \& Brown 1996 for full tabulated values)

\begin{tabular}{|c|c|c|c|c|c|c|c|}
\hline \multirow[t]{2}{*}{ Water type } & \multicolumn{5}{|c|}{$\begin{array}{l}\text { Water depth } \\
\qquad(\mathrm{m})\end{array}$} & \multirow{2}{*}{$\begin{array}{c}K_{\mathrm{d}} \text { at } \\
320 \mathrm{~nm}\end{array}$} & \multirow{2}{*}{$\begin{array}{c}\text { Linear } \\
\text { increase } \\
\text { in errors } \\
\text { with depth } \\
\quad\left(\mathrm{r}^{2}\right)\end{array}$} \\
\hline & 1 & 2 & 3 & 4 & 5 & & \\
\hline $\begin{array}{l}\text { Maldives } \\
\text { (oceanic atoll) }\end{array}$ & $\begin{array}{c}1.23 \\
(2.53)\end{array}$ & $\begin{array}{c}1.94 \\
(2.72)\end{array}$ & $\begin{array}{c}3.11 \\
(1.49)\end{array}$ & $\begin{array}{c}3.29 \\
(1.53)\end{array}$ & $\begin{array}{c}4.15 \\
(2.13)\end{array}$ & 0.389 & $\begin{array}{l}\text { Yes } \\
(0.47)\end{array}$ \\
\hline $\begin{array}{l}\text { Ko Racha Yai } \\
\text { (continental island) }\end{array}$ & $\begin{array}{c}1.81 \\
(1.71)\end{array}$ & $\begin{array}{c}4.73 \\
(1.76)\end{array}$ & $\begin{array}{l}6.54 \\
(2.66)\end{array}$ & $\begin{array}{c}9.32 \\
(2.02)\end{array}$ & $\begin{array}{l}14.73 \\
(2.07)\end{array}$ & 0.696 & $\begin{array}{l}\text { Yes } \\
(0.87)\end{array}$ \\
\hline $\begin{array}{l}\text { PMBC } \\
\text { (turbid coastal) }\end{array}$ & $\begin{array}{c}1.91 \\
(1.31)\end{array}$ & $\begin{array}{c}6.47 \\
(1.54)\end{array}$ & $\begin{array}{l}11.9 \\
(1.47)\end{array}$ & $\begin{array}{c}19.8 \\
(2.25)\end{array}$ & $\begin{array}{l}35.71 \\
(7.50)\end{array}$ & 1.479 & No \\
\hline
\end{tabular}


In the case of the Maldives and Ko Racha Yai water types, the errors increased linearly with increasing depth (Linear regression, Runs test for linearity). For the Maldives $47 \%$ of the increase could be attributed to depth factors ( $r^{2}$ value), whilst at Ko Racha Yai this dependency was even more marked $(87 \%)$. At the PMBC site the errors increased in an exponential manner, probably because of the shallow bottom depth ( $9 \mathrm{~m}$ ) and the suspended sediment composed of very fine terrigenous clay which resulted in increased turbidity closer to the sea bed. At the Maldives site, statistical testing (ANOVA and Tukey-Kramer multiple post hoc tests) indicated that significant differences in the UVB recorded by the PSF start to be detectable between the surface and $3 \mathrm{~m}$, or depth differentials of $3 \mathrm{~m}$ or more.

Data for the errors from Ko Racha Yai and PMBC were heteroscedastic and could not be transformed to permit the use of ANOVA. Initial testing of the whole depth range $(+0$ to $-5 \mathrm{~m}$ ) was therefore carried out using a Kruskal-Wallis test, followed by Dunn's multiple comparisons. For Ko Racha Yai these results indicated that errors are also detectable for depth ranges exceeding $3 \mathrm{~m}$. However, the magnitude of the errors and the associated standard deviations in Table 3 make it unlikely that Ko Racha Yai is similar to the Maldives water type. The similar result is likely to be a function of the reduced power available in the nonparametric test. Multiple 2-tailed t-tests between depths (adjusted to maintain $\alpha=0.05$, and using Welch's correction where data was heteroscedastic) indicated that differences arise at a depth range of $2 \mathrm{~m}$. Similar testing for the PMBC water type gave a value of $1 \mathrm{~m}$.

In most biological studies a systematic error of up to $+5 \%$ is likely to be quite acceptable. In these circumstances the useful depth range at each site is extended to $7 \mathrm{~m}$ at the Maldives, $2.2 \mathrm{~m}$ at Ko Racha Yai, and $1.7 \mathrm{~m}$ at PMBC. Similarly, it would also be feasible to carry out a spectroradiometer profile at the site of use of the PSF, compute the error correction required over the depth range of proposed use, and apply this to the readings from the PSF. The profile would, however, be limited to circumstances where the colour and turbidity of the water did not change significantly over the period of use.

\section{Calibration of PSF for unweighted UVB solar radiation}

The change in absorbance of PSF as measured at $330 \mathrm{~nm}$ has been shown to be proportional to the dose of monochromatic UVB radiation received. The relationship determined empirically by Diffey et al. (1982) for UVB at $297 \mathrm{~nm}$ takes the generalised form:

$$
\text { Dose }=a\left(\Delta A_{330}\right)^{b}
$$

where $a$ and $b$ are constants whose values vary according to the wavelength of the irradiating UVB source. Webb (1985) extended this calibration function to polychromatic solar UVB between the wavelengths 300 to $316 \mathrm{~nm}$ for the absorbance range 0.1 to $0.4 \Delta A_{330}$ i above $0.4 \Delta A_{330}$ she found that the film response began to depart from the calibration curve. Webb (1985) also noted that the magnitude of the calibration constants a and $b$ varied with changes in the thickness of the film, and the difference in solar spectral distribution between winter and summer for the United Kingdom. Subsequent calibrations have been made for $40 \mu \mathrm{m}$ thick film for erythemal radiation (Diffey 1989, Diffey 1997), and for solar UVB between 280 and $340 \mathrm{~nm}$ (Parisi \& Wong 1994). In these latter cases the calibration has involved a cubic polynomial function describing the dose response to a maximum of $0.45 \Delta A_{330}$. The lack of linearity exhibited in the dose response has been attributed to the protective filtering effect of the new absorption centres produced following the reaction of polysulphone with the ultraviolet radiation (Davis et al. 1976)

In this study of the newer $50 \mu \mathrm{m}$ thick film, data from the combined air calibrations and the underwater calibration were plotted graphically and curves fitted empirically using TableCurve 2D V3.05 (Jandel Scientific Software). The best fit in each case was determined from the $\mathrm{r}^{2}$ value, $F$ statistic for the overall fit, $95 \%$ confidence intervals for the parameters, and the residuals of each data point. In both calibrations the curve was a 2-term polynomial of the form:

$$
\text { Dose }=a\left(\triangle A_{330}\right)+b\left(\triangle A_{330}\right)^{3}
$$

Fig. 5 shows the fitting of the uncierwater calibration. The air calibration gave a similar plot. Values for the parameters and the quality of fits are displayed in

Table 4. Calibration curve fit statistics for $50 \mu \mathrm{m}$ PSF. All equations are in

\begin{tabular}{|c|c|c|c|c|c|c|}
\hline & Value & $\mathrm{SE}$ & $\begin{array}{l}\text { Constant } \\
95 \% \mathrm{CI}\end{array}$ & $p$ & $\begin{array}{c}F \\
\text { statistic }\end{array}$ & $\begin{array}{c}\text { No. of data } \\
\text { points }\end{array}$ \\
\hline \multicolumn{7}{|c|}{ Underwater calibration } \\
\hline$a$ & 16.89 & \pm 0.83 & 15.3 to 18.5 & $<0.0001$ & 5721 & 94 \\
\hline$b$ & 81.77 & \pm 2.9 & 76 to 87.5 & $<0.0001$ & & \\
\hline \multicolumn{7}{|c|}{ Air calibration } \\
\hline$a$ & 18.5 & \pm 0.72 & 17.1 to 19.9 & $<0.0001$ & 6437 & 112 \\
\hline$b$ & 57.1 & \pm 1.89 & 53.4 to 60.8 & $<0.0001$ & & \\
\hline
\end{tabular}
the form: Dose $=a\left(\Delta A_{3,30}\right)+b\left(\Delta A_{330}\right)^{3}$ 


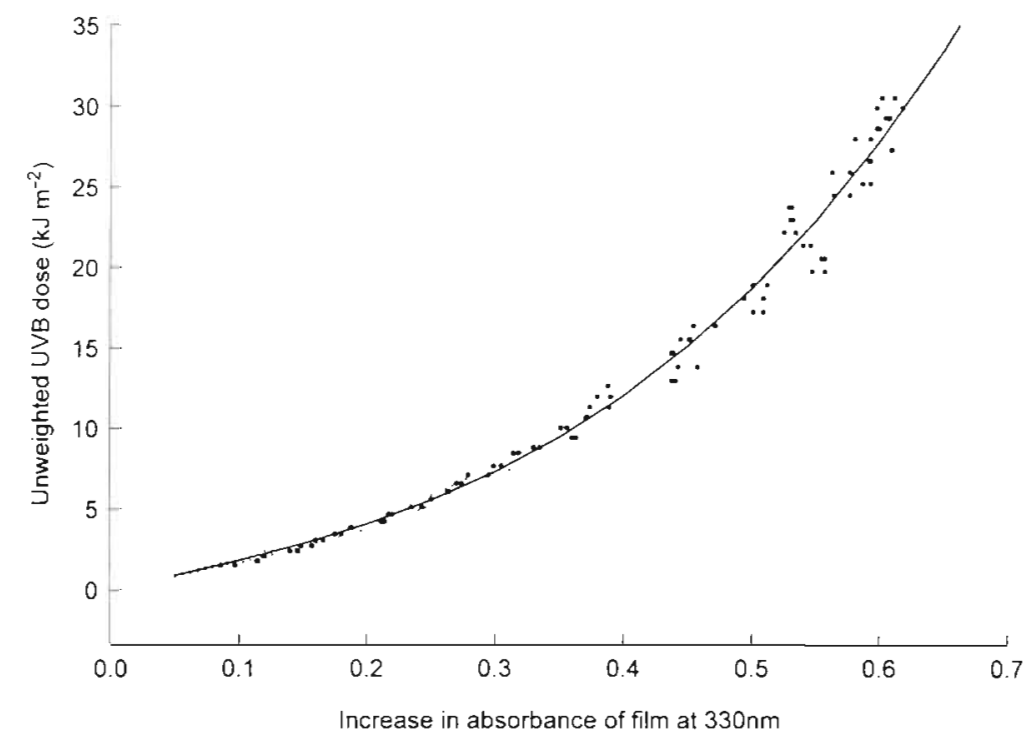

Fig. 5. Calibration curve for computing unweighted solar UVB (280 to $320 \mathrm{~nm}$ ) dose from the change in absorbance $\left(\Delta A_{330}\right)$ in PSF used underwater. Scatter points: measurements from 47 films (2 replicates each) exposed to solar radiation over the course of a clear-sky day at Phuket. Solid line: best fit curve; dotted lines: $95 \%$ confidence intervals dose. The errors in the latter typically arise from factors such as differences in the thickness and homogeneity of the film itself, and the errors from the equipment used to measure the change in absorbance. The errors in the calibration combine these errors together with others, e.g. differences in the spectral source over the time course of exposure of the film.

Errors of reliability or reproduceability have previously been considered by Diffey (1989) and Gibbs et al. (1984). Diffey (1989) defined the accuracy of computed dose in terms of the coefficient of variation derived from a number of replicate samples. Based on Diffey's (1989) cubic polynomial relationship, a comparative error has been calculated from the present data set (2 replicates for each dose) and is illustrated in Fig. 6. This can be seen to be broadly in agreement with the error given by the $95 \%$ confidence interval.

Gibbs et al. (1984) showed that the

Table 4. Because the absorbance/dose response is nonlinear, the $95 \%$ confidence interval (expressed as a percentage error in the computed dose) reduces with increasing absorbance (Fig. 6). As can be seen from the difference in the parameters of the air and underwater calibrations the same UVB dose results in a larger change in absorbance recorded by the film in air compared to its use underwater. The explanation for this is that when a translucent, diffusing material (such as PSF) is submerged in water, the change in index of refraction at the boundary of the diffusing material results in a larger percentage of the incident radiant flux being back-scattered into the water than would be back-scattered into air as a consequence of changes in interface reflections, both internal and external, combined with multiple scattering within the film (Tyler \& Smith 1970). The appropriate calibration function therefore must be used when the film is used above or below the water surface.

In any discussion of errors arising from the use of calibration curves, a distinction should be made between the errors which prevent a 'perfect fit' for a calibration relationship, and those concerned with the 'reliability' or 'reproduceability' of the PSF to record precisely the same

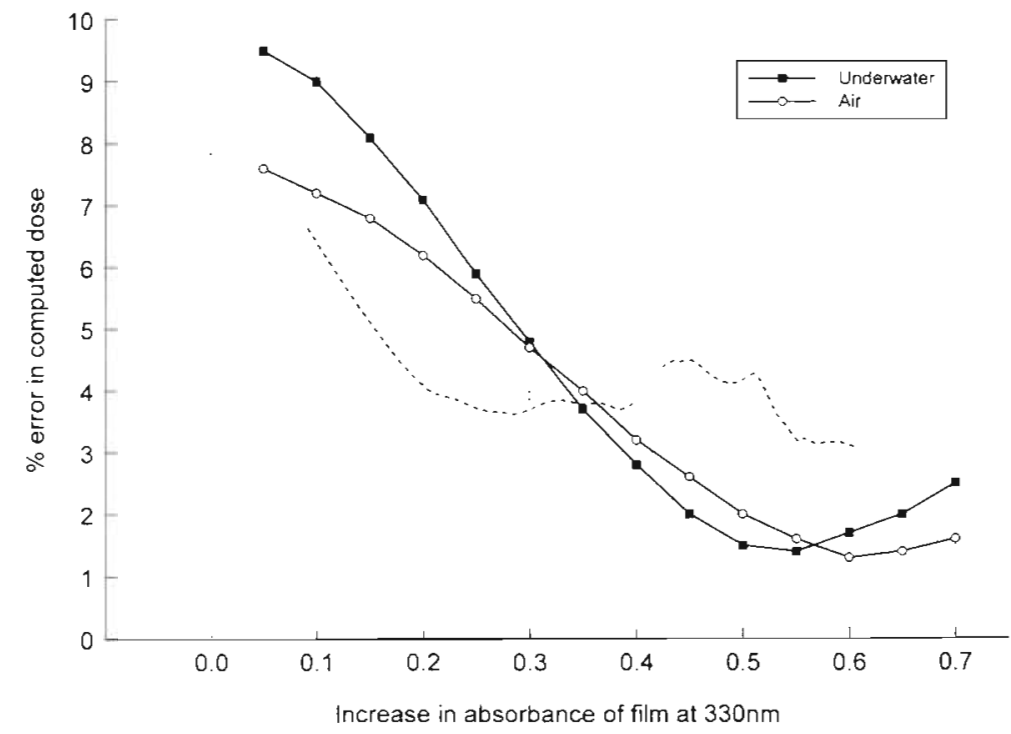

Fig. 6. Percentage error in the computed dose at the $95 \%$ confidence interval (solid lines with symbols) for the calibration equations (see Table 3 ). Dotted line: smoothed curve for the coefficient of variation (as defined by Diffey 1989) computed from 2 replicates 
mount, as in the present study, allows up to 4 replicates to be sampled across the surface of a single slide for the majority of spectrophotometers, given an adequate design of 'slide carrier'. However, in the present study 2 replicate samples gave a very high reliability of 0.99 . The large improvement in reliability might in this case be related to improvements in manufacture of the present film whereby variations in thickness and quality in the latest commercially produced $50 \mu \mathrm{m}$ film have been reduced compared to the older $40 \mu \mathrm{m}$ hand made films. Tate (1979) had reported variations in film thickness of between 0.36 and $0.44 \mu \mathrm{m}$ for older films, and Webb (1985) noted differences in the absorbance response due to this factor.

The high reliability factor and the results of the computation of the coefficient of variation both indicate that single samples of $50 \mu \mathrm{m}$ film may be used, and that the error in the unweighted UVB dose is accurately defined by the $95 \%$ confidence interval. Over the calibration range 0.1 to $0.7 \triangle A_{330}$ the overall error can be expected, therefore, to be less than $\pm 10 \%$ (95\% confidence) for use both in air and underwater (Fig. 6). Furthermore, this overall error will incorporate all errors due to changes in the solar spectrum due to variations in the sun's altitude, and arising from the variations in the properties of the film.

\section{CONCLUSIONS}

In the field of solar UVB dosimetry, polysulphone film (PSF) is a low cost, easy to use polymer film which can be deployed in all environmental settings, above and below water, to record unweighted solar UVB (280 to $320 \mathrm{~nm}$ ).

Computation of absolute UVB dose requires the measurement of the pre-and post-absorbance of the film at $330 \mathrm{~nm}$ using a spectrophotometer, and a calibration conversion function. Simple precautions are required in the choice and use of the spectrophotometer to avoid errors which arise from the opacity of the film, and give erroneously high absorbance readings due to scattering effects. Ideally the instrument should be configured to measure transmission through opaque samples (e.g. fibre optic, preying-mantis, or integrating sphere attachments), but the majority of any error can be reduced either by using baseline correction or careful alignment of the film sample in the same instrument for pre- and post-absorbance measurements.

A calibration function is required to convert the absorbance reading to a UVB dose. This function is nonlinear in the form of a 2 -termed polynomial. The reproduceability of measurements from replicate samples of
$50 \mu \mathrm{m}$ thick film is very high (0.99), and the errors in computation of the UVB dose over the range 1.5 to $40 \mathrm{~kJ} \mathrm{~m}^{-2}$ can be expected to be $< \pm 10 \%$ (95\% confidence interval), equivalent to an absorbance change of 0.1 to $0.7 \mathrm{~A}$ at $330 \mathrm{~nm}$.

Additional errors are involved where PSF is used in underwater measurements, due to changes in the spectral quality of solar UVB in different water types and at different depths. In clear oceanic waters, such as those often found around tropical coral reefs, measurements of absolute solar UVB may be made between the surface and depths of $7 \mathrm{~m}$, and comparative measurements over a range of $7 \mathrm{~m}$ at sub-surface depths, before significant errors ( $>5 \%$ ) in dose computation arise. This range decreases to $2.2 \mathrm{~m}$ in coloured clear coastal waters. At greater depth differentials PSF systematically overestimates UVB with increasing depth. If underwater spectroradiometer scans are available, however, these errors may be computed and the dose suitably adjusted, thus extending the depth deployment range of the film.

Although these depth ranges appear to be restrictive, they should be viewed in light of the requirement for UVB dosimetry and the nature of the biological communities to which this technique might be applicable. Intertidal and shallow subtidal coral reefs cover considerable areas of the tropical oceans, often in waters of exceptional clarity. Much of the biological diversity in these communities is to be found in the shallowest depths. Many of the coral species and other reef organisms have been shown to contain UVabsorbing pigments (mycosporine like amino acids) which may be present to enable them to survive the high UV irradiances which are a feature of their habitat. Differences in distribution of these pigments have been demonstrated between organisms, at different depths, and on differently oriented surfaces (Shick et al. 1996, Banaszak et al. 1998, Muszynski et al. 1998). Relating these variations to the UV environment has proven notoriously difficult and expensive to achieve with existing techniques and technologies. The use of a simple and cost-effective tool such as PSF holds out much potential to investigate these and other related areas of biological study.

Acknowledgements. I am grateful for financial support from the Natural Environment Research Council (GR9/02858) and to Professor Barbara Brown who assisted in this study. I am indebted to Professor Brian Diffey for his helpful discussions which led to this investigation. I am also particularly grateful to one anonymous reviewer whose careful and detailed work on the original manuscript significantly improved the quality of the paper. 


\section{LITERATURE CITED}

Banaszak AT, Lesser MP, Kuffner IB, Ondrusek M (1998) Relationship between ultraviolet (UV) radiation and mycosporine-like amino acids (MAAS) in marine organisms. Bull Mar Sci 63:617-628

Boelen P, Obernosterer I, Vink AA, Buma AGJ (1999) Attenuation of biologically effective UV radiation in tropical Atlantic waters measured with a biochemical DNA dosimeter. Photochem Photobiol 69:34-40

CIE (ed) (1992) Personal dosimetry of UV radiation. Commission Internationale de L'Eclairage, Vienna, Technical Report No. CIE 98

Cutchis P (1982) A formula for comparing annual damaging ultraviolet (DUV) radiation doses at tropical and mid-latitude sites. In: Calkins J (ed) NATO Conference Series, IV Marine Sciences, Vol 7: The role of solar ultraviolet radiation in marine ecosystems. Plenum Press, New York, p 213-228

Davis A (1977) The weathering of polymers. In: Grassie N (ed) Developments in polymer degradation. Applied Science Publishers, London, p 249-278

Davis A, Deane GHW, Diffey BL (1976) Possible dosimeter for ultraviolet radiation. Nature 261:169-170

Diffey BL (1989) Ultraviolet radiation dosimetry with polysulphone film. In: Diffey (ed) Biological techniques series: radiation measurements in photobiology. Academic Press, London, p 135-159

Diffey BL (1997) Monitoring personal exposure to solar ultraviolet radiation. In: Zerefos CS, Bais AF (eds) Solar ultraviolet radiation: modelling, measurements and effects. Springer-Verlag, Berlin, p 187-200

Diffey BL, Davis A, Magnus I (1982) Description and application of a personal dosimeter for measuring exposure to natural ultraviolet radiation. In: Calkins J (ed) NATO Conference Series, IV Marine Sciences, Vol 7: The role of solar ultraviolet radiation in marine ecosystems. Plenum Press, New York, p 193-204

Dunne RP (1999) Spectrophotometric measurement of chlorophyll pigments: a comparison of conventional monochromators and a reverse optic diode array design. Mar Chem 66:245-251

Dunne RP, Brown BE (1996) Penetration of solar UV-B radiation in shallow tropical waters and its potential biological effects on coral reefs; results from the central Indian Ocean and Andaman Sea. Mar Ecol Prog Ser 144:97-107

Fleischmann EM (1989) The measurement and penetration of ultraviolet radiation into tropical marine water. Limnol Oceanogr 34:1623-1629

Gibbs NK, Young AR, Corbett MF (1984) Personal solar UVR exposure: a method of increasing the reliability of measurements made with film badge dosimeters. Photodermatol Photoimmunol Photomed 1:133-136

Häder DP (1997) Impact on marine ecosystems. In: Zerefos

Editorial responsibility: Otto Kinne (Editor),

Oldendorf/Luhe, Germany
CS, Bais AF (eds) Solar ultraviolet radiation: modelling, measurements and effects. Springer-Verlag, Berlin, p $209-231$

Jagger J (1985) Solar ultraviolet actions on living cells. Praeger Scientific, New York

Jeffrey WH, Pledger RJ, Aas P, Hager S, Cofin RB, Von Haven R, Mitchell DL (1996) Diel and depth profiles of DNA photodamage in bacterioplankton exposed to ambient solar ultraviolet radiation. Mar Ecol Prog Ser 137:283-291

Karentz D, Lutze LH (1990) Evaluation of biologically harmful ultraviolet radiation in Antarctica with a biological dosimeter designed for aquatic environments. Limnol Oceanogr 35:549-561

Morales GE, Jara GP, Cabrera S (1993) Solar ultraviolet radiation measurements by $O$-nitrobenzaldehyde actinometry. Limnol Oceanogr 38:703-705

Muszynski FZ, Bruckner A, Armstrong RA, Morell JM, Corredor JE (1998) Within-colony variations of UV absorption in a reef building coral. Bull Mar Sci 63:589-594

Parisi AV, Wong JCF (1994) A dosimetric technique for the measurement of ultraviolet-radiation exposure to plants. Photochem Photobiol 60:470-474

Parisi AV, Wong JCF (1996) A new method for measurement of erythemal irradiance. Photodermatol Photoimmunol Photomed 12:171-179

Quintern LE, Horneck G, Eschweiler U, Bücker H (1992) A biofilm used as ultraviolet-dosimeter. Photochem Photobiol 55:389-395

Regan JD, Carrier WL, Gucinski H, Olla BL, Yoshida $H$, Fujimura RK, Wicklund RI (1992) DNA as a solar dosimeter in the ocean. Photochem Photobiol 56:35-42

Setlow RB (1974) The wavelengths in sunlight effective in producing skin cancer a theoretical analysis. Proc Natl Acad Sci USA 71:3363-3366

Shick JM, Lesser MP, Jokiel PL (1996) Effects of ultraviolet. radiation on corals and other coral reef organisms. Global Change Biol 2:527-545

Tate TJ (1979) Applications of polymer films to ultraviolet radiation dosimetry. MSc thesis, University of Kent, Canterbury

Tyler JE, Smith RC (1970) Measurement of spectral irradiance underwater. Gordon and Breach Science Publishers, New York

Webb AR (1985) Solar ultra-violet radiation and vitamin D synthesis in man. PhD dissertation, University of Nottingham

Wong JCF, Fleming R, Carter SJ (1989) A new dosimeter for ultraviolet-b radiation. Photochem Photobiol 50:611-615

Zerefos C (1997) Factors influencing the transmission of solar ultraviolet irradiance through the earth's atmosphere. In: Zerefos CS, Bais AF (eds) Solar ultraviolet radiation: modelling, measurements and effects. Springer-Verlag, Berlin, p $133-141$

Submitted: October 19, 1998; Accepted: June 8, 1999

Proofs received from author(s): October 27, 1999 